\title{
Anaerobic 2-ketogluconate metabolism of Klebsiella pneumoniae NCTC 418 grown in chemostat culture: involvement of the pentose phosphate pathway
}

\author{
Joost A. Simons, Jacky L. Snoep, Sjoerd Feitz, M. Joost Teixeira de Mattos \\ and OenSE M. NeIJSSEL*
}

Department of Microbiology, Biotechnology Centre, University of Amsterdam, Nieuwe Achtergracht 127, 1018 WS Amsterdam, The Netherlands

(Received 21 October 1991; accepted 25 November 1991)

\begin{abstract}
Under anaerobic 2-ketogluconate-limited growth conditions $\left(D=0 \cdot 1 \mathrm{~h}^{-1}\right)$, Klebsiella pneumoniae NCTC 418 was found to convert this carbon source to biomass, acetate, formate, $\mathrm{CO}_{2}$, ethanol and succinate. The observed fermentation pattern is in agreement with the simultaneous functioning of the pentose phosphate pathway and the Entner-Doudoroff pathway in 2-ketogluconate catabolism. When cultured at pH 8.0 apparent $\boldsymbol{Y}_{\text {ATP }}$ values were lower than those found at culture pH 6.5. This difference can be explained by assuming that at high culture pH values approximately $0.5 \mathrm{~mol}$ ATP was invested in the uptake of $1 \mathrm{~mol}$ 2-ketogluconate. Sudden relief of 2-ketogluconate-limited conditions led to lowering of the intracellular NADPH/NADP ratio and (possibly as a result of this) to inhibition of biosynthesis. Whereas production of ethanol stopped, lactate was produced at high rate. This product was formed, at least partly, via the methylglyoxal bypass.
\end{abstract}

\section{Introduction}

Organisms need to balance their NAD(P)H-producing and $\mathrm{NAD}(\mathrm{P}) \mathrm{H}$-consuming reactions. In the absence of oxygen or other exogenous electron acceptors this can be achieved by internal redox reactions that result in the excretion of products of the same degree of reduction as the substrate (e.g. lactate production from glucose) or by producing, in a strict ratio, compounds that are more oxidized and compounds that are more reduced than the substrate. For example, under carbon-limited conditions fermentation of glucose by Klebsiella pneumoniae results in the production of acetate and ethanol in a ratio of $1: 1$ (Teixeira de Mattos \& Tempest, 1983).

Under aerobic conditions, $K$. pneumoniae NCTC 418 is able to convert 2-ketogluconate intracellularly to 6-phosphogluconate by the combined action of an NADPH-dependent 2-ketogluconate reductase and gluconate kinase (Simons et al., 1991). 6-Phosphogluconate can be further catabolized via the EntnerDoudoroff pathway. In this way, 2-ketogluconate is converted to pyruvate without net $\mathrm{NAD}(\mathrm{P}) \mathrm{H}$ production (Fig. 1). However, when ammonia is used as nitrogen

\footnotetext{
- Author for correspondence. Tel. 20 5257053; fax 205255698.
}

source, reducing power will be required for the production of biomass (approximate 'molecular formula' $\mathrm{C}_{4} \mathrm{H}_{7} \mathrm{O}_{2} \mathrm{~N}$ : Herbert et al., 1971) from pyruvate:

$$
4 / 3 \mathrm{C}_{3} \mathrm{H}_{4} \mathrm{O}_{3}+1 \mathrm{NH}_{3}+4 / 3[2 \mathrm{H}] \rightarrow \mathrm{C}_{4} \mathrm{H}_{7} \mathrm{O}_{2} \mathrm{~N}+2 \mathrm{H}_{2} \mathrm{O}
$$

Therefore, anaerobic growth on 2-ketogluconate will not be possible if the Entner-Doudoroff pathway is the sole catabolic route and yet we succeeded in growing $K$. pneumoniae anaerobically on this carbon source.

To investigate how this organism generates reducing equivalents necessary for biosynthesis, we grew $K$. pneumoniae NCTC 418 anaerobically in chemostat culture under 2-ketogluconate-limited growth conditions. The effect of the culture $\mathrm{pH}$ value on 2-ketogluconate metabolism and on the activities in vitro of several enzymes possibly involved in 2-ketogluconate metabolism was studied. Furthermore, we report on the effects of a sudden increase in the 2-ketogluconate concentration under anaerobic 2-ketogluconate-limited conditions.

\section{Methods}

\footnotetext{
Micro-organism and growth conditions. Klebsiella pneumoniae NCTC 418 was maintained by subculture on tryptic meat-digest agar slopes.
} 
Organisms were cultured in a Porton-type chemostat with a working volume of approximately $500 \mathrm{ml}$, stirred at about 1000 r.p.m., or in a Multigen chemostat (New Brunswick Scientific) with a working volume of $300 \mathrm{ml}$ (Herbert et al., 1965). In order to obtain 2-ketogluconate-limited growth conditions, simple salts medium was used as specified by Evans et al. (1970), but instead of citrate nitrilotriacetic acid ( $2 \mathrm{~mm}$ ) was used as chelator. The medium contained approximately $50 \mathrm{~mm}$-2-ketogluconate. This carbon source was sterilized by filtration (Seitz filter plates type EKS). The dilution rate $D$ was set at $0 \cdot 10 \pm 0.01 \mathrm{~h}^{-1}$. The $\mathrm{pH}$ value of the culture was maintained automatically at a preset value $\pm 0 \cdot 1 \mathrm{pH}$ unit, using sterile $2 \mathrm{M}-\mathrm{NaOH}$, and the temperature was maintained at $35^{\circ} \mathrm{C}$. To prevent excessive foaming silicone antifoaming agent (BDH; $1 \%$ w/v) was added at a rate of approximately $0.5 \mathrm{ml} \mathrm{h}^{-1}$. Anaerobiosis was maintained by the method described by Teixeira de Mattos $\&$ Tempest (1983).

Pulse experiments. Pulse experiments were performed as described previously (Simons et al., 1991). The initial 2-ketogluconate concentration was approximately $15 \mathrm{~mm}$.

Preparation of 2-ketogluconate. 2-Ketogluconate was prepared by a microbiological method in which sodium gluconate was oxidized by a strain of Pseudomonas putida, as described previously (Simons et al., 1991).

Preparation of cell-free extracts. Cell-free extracts were prepared according to Hommes et al. (1985). The buffer used throughout the preparation was $10 \mathrm{~mm}$-sodium phosphate (pH 6.0) containing $5 \mathrm{~mm}$ $\mathrm{MgCl}_{2}$, except in the case of preparing cell-free extracts for measuring methylglyoxal synthase activity. In the latter case, cells were washed with and resuspended in demineralized water.

Enzyme assays. Gluconate kinase was assayed according to Bergmeyer et al. (1974a), as modified by Leegwater (1983). 2-Ketogluconate reductase was assayed as described previously (Simons et al., 1991). Isocitrate lyase activity was measured as described by Dixon \& Kornberg (1959). 6-Phosphogluconate dehydrogenase was assayed according to Bergmeyer et al. (1974b) and glucose-6-phosphate dehydrogenase according to Löhr \& Waller (1974). Transhydrogenase activities were determined according to Sweetman \& Griffiths (1971). D-Lactate dehydrogenase was determined as described by Streekstra $e t$ al. $(1987 \mathrm{~b})$. Methylglyoxal synthase was measured as the rate of disappearance of dihydroxyacetone phosphate in the absence of nucleotide cofactors, according to Hopper \& Cooper (1971) as modified by Streekstra (1990). Glyoxalase activity was measured in intact cells following the procedure of Cooper \& Anderson (1970). The assays were performed at $35^{\circ} \mathrm{C}$ with a Beckman DU 40 spectrophotometer. One Unit is defined as the amount of enzyme catalysing the conversion of $1 \mu \mathrm{mol}$ substrate $\min ^{-1}$.

Measurement of NADPH and NADP levels. NADPH was extracted from a culture sample with $\mathrm{KOH}(0.15-0.2 \mathrm{M}$; extraction $\mathrm{pH}$ approximately 12.5 ). NADP was extracted from a culture sample with $\mathrm{HCl}(0.15-0.2 \mathrm{M}$; extraction $\mathrm{pH}$ approximately 1.5$)$. Samples were taken from these extraction solutions and kept at room temperature (NADPH) or boiled (NADP) for $10 \mathrm{~min}$. Cell debris was removed by centrifugation $(3000 \mathrm{~g}, 10 \mathrm{~min})$. The acid extract was brought to $\mathrm{pH} 6.5$ and the alkaline extract to $\mathrm{pH} 7 \cdot 5$. Determination of the nucleotides was based on the microcycling assay for NAD(H) of Bernofsky \& Swan (1973) and was performed by adding $500 \mu 1 \mathrm{H}_{2} \mathrm{O}, 100 \mu$ glycylglycine (1 M, pH 8.0), $50 \mu 1$ 3-(4,5-dimethylthiazo-2-yl)-2,5-diphenyltetrazolium bromide (MTT) $(8.4 \mathrm{mM}), 50 \mu \mathrm{l}$ phenazine ethosulphate ( $33.2 \mathrm{mM}$ ) and $50 \mu \mathrm{l}$ glucose 6-phosphate $(20 \mathrm{mM})$ to $300 \mu \mathrm{l}$ of the neutralized extraction solution. After $3 \mathrm{~min}, 50 \mu \mathrm{l}$ glucose-6-phosphate dehydrogenase $\left(70 \mathrm{U} \mathrm{ml}^{-1}\right)$ was added and the rate of MTT reduction was followed spectrophotometrically at $570 \mathrm{~nm}$. Calibration was performed by adding $0,0.2,0.5$ or $1.0 \mu \mathrm{M}-\mathrm{NADPH}$ or -NADP to the extraction solutions at the beginning of the extraction procedure. The assay was performed at $35^{\circ} \mathrm{C}$ with a Beckman DU 40 spectrophotometer.

Analyses. Bacterial dry weight was measured by the method of Herbert et al. (1971). Protein was determined according to Gornall $e t$ al. (1949). 2-Ketogluconate, acetate, lactate, succinate, formate and ethanol concentrations were determined by HPLC (LKB) with an Aminex HPX 87H organic acids column (Bio-Rad) at a temperature of $65^{\circ} \mathrm{C}$ with $5 \mathrm{~mm}-\mathrm{H}_{2} \mathrm{SO}_{4}$ as eluent, using a 2142 refractive index detector (LKB) and an SP 4270 integrator (Spectra Physics). $\mathrm{CO}_{2}$ produced by the cultures was determined by passing the gas from the fermenter through a $\mathrm{CO}_{2}$ analyser (Servomex IR gas analyser PA 404).

Calculations. The specific rate of $\mathrm{NAD}(\mathrm{P}) \mathrm{H}$ oxidation was calculated, using equation (1) (see Introduction) and the fermentation scheme given in Fig. $1 a, b$ :

$$
q_{\mathrm{NAD}(\mathrm{P})}=q_{2 \text {-ketogluconate }}+4 / 3 q_{\text {biomass }}+2 q_{\text {succinate }}+2 q_{\text {ethanol }}
$$

Assuming that the flux through the pentose phosphate pathway [ $\left.q_{\mathrm{CO}_{2}}(\mathrm{PP})\right]$ equals the rate of $\mathrm{CO}_{2}$ production that cannot be explained by cleavage of formate and production of succinate $\left[q_{\mathrm{CO}_{2}}(\mathrm{PP})=\right.$ $q_{\mathrm{CO}_{2}}$ (observed) $+q_{\text {formate }}+q_{\text {succinate }}-q_{\text {acetate }}-q_{\text {ethanol }}$, the rate of $N A D(P)$ reduction can be calculated using the following equation:

$$
q_{\mathrm{NAD}(\mathrm{P}) \mathrm{H}}=q_{2 \text {-ketogluconate }}+5 / 3 q_{\mathrm{CO}_{2}}(\mathrm{PP})
$$

This calculation is valid both for the functioning of the pentose phosphate pathway as shown in Fig. $1(a)$ and for the cyclic operation of this route (i.e. 6-phosphogluconate is resynthesized from fructose 6-phosphate and glyceraldehyde 3-phosphate by the gluconeogenic pathway and glucose-6-phosphate dehydrogenase). When lactate is produced via the methylglyoxal bypass, $q_{\mathrm{NAD}(\mathrm{P}) \mathrm{H}}$ can be calculated by subtracting $q_{\text {lactate }}$ from equation (3). Redox balances $(\% \mathrm{H})$ were calculated as $q_{\mathrm{NAD}(\mathrm{P}) \mathrm{H}} / q_{\mathrm{NAD}(\mathrm{P})} \times 100$.

For the calculation of specific rates of ATP production $\left(q_{\mathrm{ATP}}\right)$ it was assumed that an ATP-dependent transhydrogenase, consuming 1 ATP/NADPH formed, served to generate the NADPH (necessary for 2-ketogluconate reduction and biomass formation) that was not produced by the action of the pentose phosphate pathway, that is $q_{2 \text {-ketogluconate }}+4 / 3 q_{\text {biomass }}-q_{\mathrm{CO}_{2}}(\mathrm{PP})$. Thus (see Fig. $\left.1 a, b\right), q_{\mathrm{ATP}}=$ $q_{\text {acetate }}+q_{2 \text {-ketogluconate }}(\mathrm{ED})+5 / 3 q_{\mathrm{CO}_{2}}(\mathrm{PP})-\left[q_{2 \text {-ketogluconate }}+4 / 3 q_{\text {biomass }}\right.$ $\left.-q_{\mathrm{CO}_{2}}(\mathrm{PP})\right]$, where $q_{2 \text {-ketogluconate }}(\mathrm{ED})=q_{2 \text {-ketogluconate }}-q_{\mathrm{CO}_{2}}(\mathrm{PP})$ is the flux through the Entner-Doudoroff pathway. It follows that:

$$
q_{\mathrm{ATP}}=q_{\text {acetate }}+5 / 3 q_{\mathrm{CO}_{2}}(\mathrm{PP})-4 / 3 q_{\text {biomass }}
$$

When lactate is formed via the methylglyoxal bypass $q_{\text {ATP }}$ can be calculated by subtracting $2 q_{\text {lactate }}$ from equation (4).

\section{Results and Discussion}

Klebsiella pneumoniae NCTC 418 was found to be able to use 2-ketogluconate as the sole carbon and energy source under anaerobic conditions. Just as under aerobic conditions, cells could convert this carbon source, after it had been taken up, to 6-phosphogluconate by means of an NADPH-dependent 2-ketogluconate reductase and gluconate kinase (Table 1). Since catabolism via the Entner-Doudoroff pathway does not deliver the reducing power necessary for production of biomass from 2-ketogluconate, other pathways must (also) be involved in the anaerobic catabolism of this carbon source. 
(a)

2-Ketogluconate<smiles>CC(C)C(C)NNc1ccccc1</smiles>

6-Phosphogluconate<smiles>C=CC</smiles>

2-Keto-3-deoxy6-phosphogluconate

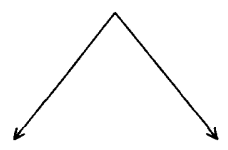

Glyceraldehyde 3-phosphate<smiles>[Y10]C1CC1N(O)O</smiles>

Pyruvate
2-Ketogluconate<smiles>CC(C)C(C)NNc1ccccc1</smiles>

6-Phosphogluconate

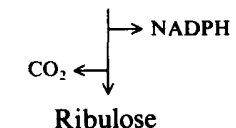

Ribulose

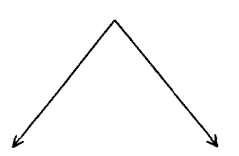

1/3Glyceraldehyde 2/3Fructose 3-phosphate 6-phosphate

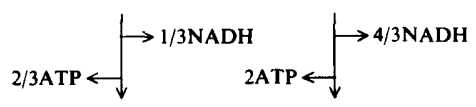

1/3Pyruvate 4/3Pyruvate (b)

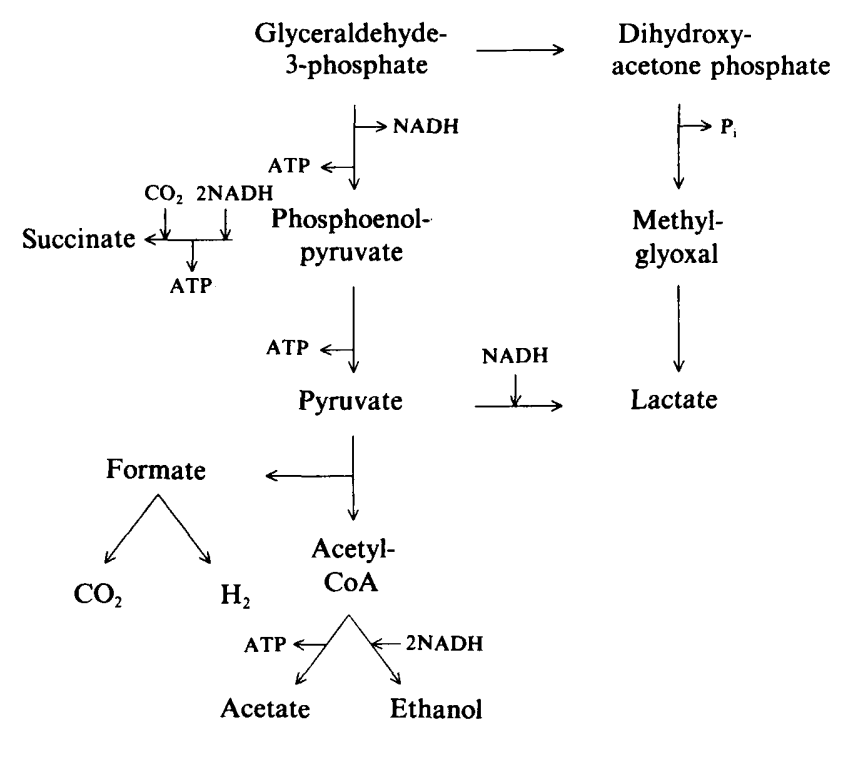

Fig. 1. ATP- and NAD(P)H-consuming and producing reactions in the conversion of 2-ketogluconate to pyruvate via the EntnerDoudoroff pathway or the pentose phosphate pathway $(a)$ and in the formation of fermentation products $(b)$.

Table 1. Specific enzyme activities in $K$. pneumoniae NCTC 418, grown anaerobically in chemostat culture under 2-ketogluconate limitation

$D=0 \cdot 1 \mathrm{~h}^{-1}$. Glyoxalase activity in mmol (g dry weight) $)^{-1} \mathrm{~h}^{-1} ;$ all other activities in Units (mg protein) ${ }^{-1}$. Values given are means of the number of experiments indicated, $\pm \mathrm{SD}$.

\begin{tabular}{|c|c|c|c|}
\hline \multirow[b]{2}{*}{ Enzyme } & \multirow{2}{*}{$\begin{array}{c}\text { No. of } \\
\text { experiments, } n\end{array}$} & \multicolumn{2}{|c|}{ Specific activity } \\
\hline & & pH 6.5 & pH 8.0 \\
\hline 2-Ketogluconate reductase & 3 & $0.59 \pm 0.04$ & $1.05 \pm 0.07$ \\
\hline $\begin{array}{l}\text { Gluconate kinase } \\
\text { 6-Phosphogluconate }\end{array}$ & 3 & $0.02 \pm 0.00$ & $0.03 \pm 0.00$ \\
\hline $\begin{array}{l}\text { dehydrogenase } \\
\text { Glucose-6-phosphate }\end{array}$ & 3 & $0.18 \pm 0.03$ & $0.13 \pm 0.02$ \\
\hline $\begin{array}{l}\text { dehydrogenase } \\
\text { Transhydrogenase }\end{array}$ & 3 & $0.14 \pm 0.03$ & $0.08 \pm 0.03$ \\
\hline (ATP-dependent) & 3 & $0.01 \pm 0.01$ & $<0.01 \pm 0.00$ \\
\hline $\begin{array}{l}\text { Transhydrogenase } \\
\text { (ATP-independent) }\end{array}$ & 3 & $0.01 \pm 0.01$ & $<0.01 \pm 0.00$ \\
\hline D-Lactate dehydrogenase & 2 & $0.51 \pm 0.03$ & $1.29 \pm 0.07$ \\
\hline Methylglyoxal synthase & 2 & $0.18 \pm 0.02$ & $0 \cdot 11 \pm 0.01$ \\
\hline Glyoxalase & 2 & $3.2 \pm 0.2$ & $2 \cdot 4 \pm 0 \cdot 1$ \\
\hline
\end{tabular}

To investigate the anaerobic metabolism of 2-ketogluconate by $K$. pneumoniae NCTC 418 , we grew this organism in chemostat culture under 2-ketogluconatelimited conditions. It was found that 2-ketogluconate was converted to biomass, acetate, formate, $\mathrm{CO}_{2}$, ethanol and succinate (Table 2). This latter product was
Table 2. Specific rates in steady state and after pulsing 2-ketogluconate of 2-ketogluconate consumption and product formation [in mmol ( $g$ dry weight $)^{-1} h^{-1}$ ] by $K$. pneumoniae NCTC 418, grown anaerobically in chemostat culture under

\section{2-ketogluconate-limited conditions}

$D=0 \cdot 1 \mathrm{~h}^{-1}$. Data are mean values of five measurements. Standard deviations are given in brackets. $q_{\mathrm{CO}_{2}}(\mathrm{PP})$, specific rate of $\mathrm{CO}_{2}$ production via the pentose phosphate pathway. Lactate production was assumed to result from methylglyoxal bypass activity. $Y_{\text {ATP }}$ is given in $\mathrm{g}$ dry wt (mol ATP formed) ${ }^{-1} \cdot{ }^{*} Y_{\text {ATP }}$ assuming $0.5 \mathrm{ATP}$ was invested per 2-ketogluconate taken up.

\begin{tabular}{|c|c|c|c|c|}
\hline & \multicolumn{2}{|c|}{ pH 6.5 } & \multicolumn{2}{|c|}{ pH 8.0 } \\
\hline & Steady state & Pulse & Steady state & Pulse \\
\hline$q_{\text {2-ketogluconate }}$ & $6 \cdot 5(0 \cdot 2)$ & $11 \cdot 7$ & $8 \cdot 3(0.4)$ & $12 \cdot 4$ \\
\hline$\mu$ & $0 \cdot 10$ & 0 & $0 \cdot 10$ & 0 \\
\hline$q_{\mathrm{CO}_{2}}$ & $12.0(0.6)$ & $16 \cdot 5$ & $7.2(0.6)$ & $10 \cdot 7$ \\
\hline$q_{\text {formate }}$ & 0 & 0 & $9 \cdot 1(0 \cdot 6)$ & $9 \cdot 0$ \\
\hline$q_{\text {acetate }}$ & $8 \cdot 1(0 \cdot 5)$ & $13 \cdot 7$ & $8 \cdot 1(0.4)$ & 11.7 \\
\hline$q_{\text {ethanol }}$ & $1.4(0.2)$ & 0 & $3.3(0.2)$ & 0 \\
\hline$q_{\text {lactate }}$ & 0 & $6 \cdot 0$ & 0 & 6.0 \\
\hline$q_{\text {succinate }}$ & $0.2(0.0)$ & 1.5 & $0.6(0.0)$ & 1.5 \\
\hline$\% \mathrm{C}$ & $92.0(1.9)$ & 97 & $91.9(1.3)$ & 90 \\
\hline$q_{\mathrm{CO}_{2}}(\mathrm{PP})$ & $2.6(0.5)$ & $4 \cdot 3$ & $5.4(0.4)$ & $6 \cdot 2$ \\
\hline$\% \mathrm{H}$ & $96.9(5.4)$ & 88 & $98.9(2.8)$ & 109 \\
\hline$q_{\text {ATP }}$ & $11 \cdot 1(0.8)$ & 8.9 & $15.7(0.9)$ & $10 \cdot 1$ \\
\hline$Y_{\text {ATP }}$ & 9.0 & 0 & $6 \cdot 4 / 8 \cdot 7^{*}$ & 0 \\
\hline
\end{tabular}

not formed via the glyoxylate shunt, since no isocitrate lyase activity was detectable in these cells. So, not only was reducing power invested in the production of 
biomass, but also in the formation of ethanol and succinate. If the Entner-Doudoroff pathway was the sole catabolic route, the rate of $\mathrm{NAD}(\mathrm{P})$ reduction would equal the rate of 2-ketogluconate consumption (see Fig. 1 a). It can be calculated that the actual rate of NAD $(\mathrm{P}) \mathrm{H}$ oxidation was about twice the rate at which NAD(P) could be reduced by the sole functioning of this pathway in 2-ketogluconate catabolism.

It has been observed for growth of $K$. pneumoniae on a variety of carbon sources that the measured rate of $\mathrm{CO}_{2}$ production closely agrees with the rate that can be calculated from the fermentation pathways (Teixeira de Mattos \& Tempest, 1983; Streekstra et al., 1987a), indicating that the net effect on $\mathrm{CO}_{2}$ production of $\mathrm{CO}_{2}$ fixing and -producing steps in biomass formation by this organism is negligible. However, the observed $\mathrm{CO}_{2}$ production rate for growth on 2-ketogluconate was significantly higher than would be the case if cleavage of formate and production of succinate, respectively, were the only $\mathrm{CO}_{2}$-producing and -consuming reactions.

An explanation for the apparent discrepancy between the rate of $N A D(P)$ reduction and $N A D(P) H$ oxidation would be that NAD is reduced by anaerobic activity of the pyruvate dehydrogenase complex. Recently, this enzyme system was found to be active under anaerobic conditions in Enterococcus faecalis when this organism was grown on pyruvate (Snoep et al., 1990). However, functioning of this enzyme complex in 2-ketogluconate catabolism does not explain the discrepancy between observed and calculated $\mathrm{CO}_{2}$ production rates, since the $\mathrm{CO}_{2}$ production accompanying pyruvate oxidation would still equal $q_{\text {acetate }}+q_{\text {ethanol }}-q_{\text {formate }}$.

$A$ route that results in the generation of both $\mathrm{NAD}(\mathrm{P}) \mathrm{H}$ and $\mathrm{CO}_{2}$ is the pentose phosphate pathway. Activities in vitro of the (NADP-dependent) key enzymes 6-phosphogluconate dehydrogenase and glucose-6-phosphate dehydrogenase were detectable in cell-free extracts from $K$. pneumoniae that had been grown anaerobically on 2-ketogluconate (Table 1) and were significantly higher than those found under (anaerobic) glucose limitation [pH 6.5, $D=0.1 \mathrm{~h}^{-1}$ : 6-phosphogluconate dehydrogenase and glucose-6-phosphate dehydrogenase activities were 0.08 and $0.07 \mathrm{U}$ (mg protein $)^{-1}$ respectively].

If 2-ketogluconate were catabolized partly by means of the pentose phosphate pathway the ratio of 'extra' $\mathrm{NAD}(\mathrm{P}) \mathrm{H} / \mathrm{CO}_{2}$ produced would be $5 / 3$ (Fig. $1 a$ ). Indeed, at both culture $\mathrm{pH}$ values tested this ratio was found to be 1.7 and when it was assumed that the $\mathrm{CO}_{2}$ production that cannot be explained by cleavage of formate and production of succinate resulted from activity of the pentose phosphate pathway the redox balances were found to be $97 \%(\mathrm{pH} \mathrm{6.5)}$ ) and $99 \%$ (pH 8.0), respectively (Table 2). Therefore, we conclude that the Entner-Doudoroff pathway and the pentose phosphate pathway function simultaneously in the anaerobic catabolism of 2-ketogluconate. The calculated flux through the latter pathway was, respectively, $42 \%$ (pH 6.5) and $66 \%(\mathrm{pH} \mathrm{8.0)}$ of the total flux of 2-ketogluconate catabolism.

The reason for the importance of this route in the (anaerobic) catabolism of 2-ketogluconate may reside in the fact that $K$. pneumoniae first has to reduce this carbon source in an NADPH-dependent reaction. So, NADPH must be produced at high specific rates to sustain both anabolism and catabolism of 2-ketogluconate, whereas only low specific transhydrogenase activities in vitro could be detected in these cells, especially at a high culture $\mathrm{pH}$ value (Table 1). Thus, the probable function of this route is to provide NADPH. A consequence of the functioning of the pentose phosphate pathway is that the conversion of 2-ketogluconate to pyruvate is accompanied by net NADH production. Therefore, to maintain redox neutrality, reduced compounds like ethanol and succinate have to be produced.

An interesting observation is that the yield on 2-ketogluconate was higher at $\mathrm{pH} 6.5$ than at $\mathrm{pH} 8.0$. This difference cannot be explained by a shift in fermentation pattern, leading to a decrease in the amount of ATP produced per 2-ketogluconate catabolized. On the contrary, it can be calculated that more ATP per 2-ketogluconate was synthesized at high culture $\mathrm{pH}$ values $(1.9 \mathrm{ATP} / \mathrm{KGA}$ at $\mathrm{pH} 8.0$ and $1.7 \mathrm{ATP} / \mathrm{KGA}$ at $\mathrm{pH}$ 6.5). Thus, as can be seen in Table 2, the apparent $Y_{\text {ATP }}$ values for cells growing under 2-ketogluconate limitation were lower at high culture $\mathrm{pH}$ values. With anaerobic gluconate-limited cultures of $K$. pneumoniae similar observations were made and these were explained by postulating that at high culture $\mathrm{pH}$ values $0.5 \mathrm{~mol}$ ATP was invested in the uptake of $1 \mathrm{~mol}$ gluconate (Streekstra et al., 1987a). This is in agreement with the suggestion that, in Escherichia coli, at low pH (5.5) one proton is taken up per mol of (undissociated) organic acid transported, whereas at high $\mathrm{pH}(7.5)$ two protons are taken up per mol of acid, one in association with the substrate itself and one in association with the carrier molecule (Ramos \& Kaback, 1977). The observed pH dependence of apparent $Y_{\mathrm{ATP}}$ values for growth of $K$. pneumoniae on 2-ketogluconate is in agreement with this hypothesis. Indeed, in order to obtain equal $Y_{\mathrm{ATP}}$ values for both acid and alkaline growth conditions $0.55 \mathrm{~mol}$ ATP has to be taken into account for the uptake of $1 \mathrm{~mol}$ 2-ketogluconate under the latter conditions. In conclusion, the data presented provide evidence that at high culture pH values approximately $0.5 \mathrm{~mol}$ ATP is invested in the uptake of $1 \mathrm{~mol}$ 2-ketogluconate.

When, under aerobic conditions, a 2-ketogluconatelimited culture of $K$. pneumoniae was suddenly relieved of 
Table 3. Effect of pulsing 2-ketogluconate on levels of NADPH and NADP in an anaerobic 2-ketogluconate-limited chemostat culture of $K$. pneumoniae NCTC 418

$D=0 \cdot 1 \mathrm{~h}^{-1}, \mathrm{pH} 6 \cdot 5$. Nucleotide levels were determined in steady state and at 10 and $30 \mathrm{~min}$ after pulsing 2-ketogluconate. Values given are means $\pm \mathrm{SD}$. At steady state the number of experiments, $n$, was 3 for [NADPH] and 2 for [NADP] and [NADPH]/[NADP]. At $t=10 \mathrm{~min}, n=2$ and at $t=30 \mathrm{~min}, n=1$.

\begin{tabular}{lccc}
\hline \hline & $\begin{array}{c}{[\mathrm{NADPH}]} \\
{[\mu \mathrm{mol}(\mathrm{g} \text { dry wt) }}\end{array}$ & $\begin{array}{c}{[\mathrm{NADP}]} \\
\end{array}$ & {$[\mathrm{NADPH}] /[\mathrm{NADP}]$} \\
\hline Steady state & $0.36 \pm 0.03$ & $0.46 \pm 0.00$ & $0.79 \pm 0.05$ \\
$t=10 \mathrm{~min}$ & $0.21 \pm 0.02$ & $0.63 \pm 0.01$ & $0.33 \pm 0.02$ \\
$t=30 \mathrm{~min}$ & 0.26 & 0.60 & 0.43 \\
\hline \hline
\end{tabular}

its limitation (a so-called pulse experiment) cells reacted by catabolizing this carbon source at a highly elevated rate, whereas growth came to a complete standstill. It was suggested that this growth inhibition was caused by a depletion of the NADPH pool, due to the high rate at which NADPH was now oxidized by 2-ketogluconate reductase (Simons et al., 1991). Addition of excess 2-ketogluconate to a 2-ketogluconate-limited culture of $K$. pneumoniae under anaerobic conditions had the same inhibitory effect on biosynthesis (Table 2). Again, after a pulse the specific rate of 2-ketogluconate catabolism (and thus the rate of NADPH oxidation) was increased. Measurements of intracellular levels of NADPH and NADP revealed that addition of excess 2-ketogluconate led to a decrease in the NADPH level and (thus) a concomitant increase in the NADP level (Table 3). As a result of the 2-ketogluconate pulse, the intracellular NADPH/NADP ratio was lowered by a factor of $2 \cdot 4$. Thus the growth inhibiting effect of a sudden excess of 2-ketogluconate could indeed be mediated by a decrease in the NADPH level or the NADPH/NADP ratio in the cell.

The calculated flux through the pentose phosphate pathway increased when 2-ketogluconate was pulsed, but not to the same extent as the rate of 2-ketogluconate catabolism. Thus, the relative contribution of the pentose phosphate pathway to 2-ketogluconate catabolism was lowered. Whereas specific production rates of $\mathrm{CO}_{2}$, acetate and succinate were increased, production of ethanol stopped (Table 2). The generated reducing power was now disposed of by production of lactate, a product also found under aerobic conditions after 2-ketogluconate addition (Simons et al., 1991). Lactate could be formed via two distinct pathways (see Fig. $1 b$ ); from pyruvate by the soluble (NAD-linked) D-lactate dehydrogenase (pyruvate reductase; Garvie, 1980) or via the so-called methylglyoxal bypass. This latter pathway, consisting of the enzymes methylglyoxal synthase and glyoxalase (see Cooper, 1984), can convert dihydroxyacetone phosphate into D-lactate without accompanying ATP production, thereby enabling cells to uncouple ATP generation from catabolism. The production of lactate by $K$. pneumoniae after relief of carbon limitation under anaerobic conditions is well-known and has been ascribed to activity of the latter pathway (Teixeira de Mattos et al., 1984). The relevant enzymes of both lactate-producing pathways were found to be present in cell-free extracts from $K$. pneumoniae that had been grown anaerobically on 2-ketogluconate (Table 1). However, since growth of $K$. pneumoniae stopped when 2-ketogluconate was pulsed to a 2-ketogluconate-limited culture, one would expect the energy requirement of the cells to decrease. If it is assumed that all of the lactate produced after a 2-ketogluconate pulse was formed via the methylglyoxal bypass the calculated specfic rate of ATP production was indeed lowered (Table 2). However, if one assumes lactate production by means of lactate dehydrogenase this would lead to an almost doubling of the specific ATP production rate as compared to steady-state conditions. These calculations strongly suggest that lactate production by $K$. pneumoniae in response to a 2-ketogluconate pulse is the result of methylglyoxal bypass activity.

In conclusion, the data presented in this work provide evidence that in $K$. pneumoniae the pentose phosphate pathway plays an important role in the anaerobic catabolism of 2-ketogluconate. Sudden relief of 2-ketogluconate-limited conditions leads to an increase in the rate of 2-ketogluconate catabolism and (possibly as a result of the accompanying decrease in the intracellular NADPH/NADP ratio) to inhibition of biosynthesis. Since anabolism and catabolism are now totally uncoupled, some form of energy dissipation has to take place. Most likely, this is effected by production of lactate via the methylglyoxal bypass.

\section{References}

Bergmeyer, H. U., GaWehn, K. \& Grassl, M. (1974a). Enzyme als biochemische Reagentien. Gluconat-kinase. In Methoden der Enzymatischen Analyse, 3rd edn, vol. 1, p. 485. Edited by H. U. Bergmeyer. Weinheim: Verlag Chemie.

Bergmeyer, H. U., Gawehn, K. \& Grassl, M. (1974b). Enzyme als biochemische Reagentien. 6-Phosphogluconat-dehydrogenase. In Methoden der Enzymatischen Analyse, 3rd edn, vol. 1, p. 533. Edited by H. U. Bergmeyer. Weinheim: Verlag Chemie.

BERNOFSKY, C. \& SWAN, M. (1973). An improved cycling assay for nicotinamide adenine dinucleotide. Analytical Biochemistry 53, $452-458$.

COOPER, R. A. (1984). Metabolism of methylglyoxal in microorganisms. Annual Review of Microbiology 38, 49-68.

COOPER, R. A. \& ANDERSON, A. (1970). The formation and catabolism of methylglyoxal during glycolysis in Escherichia coli. FEBS Letters 11, 273-276. 
Dixon, G. H. \& KoRnBerg, H. L. (1959). Assay methods for keyenzymes of the glyoxylate cycle. Biochemical Journal 72, 3P.

Evans, C. G. T., Herbert, D. \& Tempest, D. W. (1970). The continuous cultivation of micro-organisms. II. Construction of a chemostat. Methods in Microbiology 2, 277-327.

GARVIE, E. I. (1980). Bacterial lactate dehydrogenases. Microbiological Reviews 44, 106-139.

Gornall, A. G., Bardawill, C. J. \& David, M. A. (1949). Determination of serum proteins by means of the biuret reaction. Journal of Biological Chemistry 177, 751-766.

Herbert, D., Phipps, P. J. \& Tempest, D. W. (1965). The chemostat: design and instrumentation. Laboratory Practice 14, 1150-1161.

Herbert, D., Phipps, P. J. \& Strange, R. E. (1971). Chemical analysis of microbial cells. Methods in Microbiology 5B, 209-344.

Hommes, R. W. J., van Hell, B., Postma, P. W., Neijssel, O. M. \& TEMPEST, D. W. (1985). The functional significance of glucose dehydrogenase in Klebsiella aerogenes. Archives of Microbiology 143, 163-168.

HOPPER, D. J. \& COOPER, R. A. (1971). The regulation of Escherichia coli methylglyoxal synthase; a new control site in glycolysis? FEBS Letters 13, 213-216.

LEEGWATER, M. P. M. (1983). Microbial reactivity: its relevance to growth in natural and artificial environments, pp. 46-47. $\mathrm{PhD}$ thesis, University of Amsterdam, The Netherlands.

LÖHR, G. W. \& WALLER, H. D. (1974). Glucose-6-phosphatdehydrogenase. In Methoden der Enzymatischen Analyse, 3rd edn, vol. 1, pp. 673-681. Edited by H. U. Bergmeyer. Weinheim: Verlag Chemie.

RAMOS, S. \& KABACK, H. R. (1977). The relationship between the electrochemical $\mathrm{H}^{+}$gradient and active transport in Escherichia coli membrane vesicles. Biochemistry 16, 854-858.

Simons, J. A., TeiXeira de Mattos \& Neijssel, O. M. (1991). Aerobic 2-ketogluconate metabolism of Klebsiella pneumoniae 418 grown in chemostat culture. Journal of General Microbiology 137, 1479-1483.

Snoep, J. L., Teixeira de Mattos, M. J., Postma, P. W. \& Neijssel, O. M. (1990). Involvement of pyruvate dehydrogenase in product formation in pyruvate-limited anaerobic chemostat cultures of Enterococcus faecalis NCTC 775. Archives of Microbiology 154, $50-55$.

STREEKSTRA, H. (1990). Metabolic uncoupling in anaerobic Klebsiella pneumoniae. PhD thesis, University of Amsterdam, The Netherlands.

Streekstra, H., Buurman, E. T., Hoitink, C. W. G., Teixeira de Mattos, M. J., Neijssel, O. M. \& Tempest, D. W. (1987a). Fermentation shifts and metabolic reactivity during anaerobic carbon-limited growth of Klebsiella aerogenes NCTC 418 on fructose, gluconate, mannitol and pyruvate. Archives of Microbiology 148, $137-143$.

Streekstra, H., Teixeira de Mattos, M. J., Neijssel, O. M. \& TEMPEST, D. W. (1987b). Overflow metabolism during anaerobic growth of Klebsiella pneumoniae NCTC 418 on glycerol and dihydroxyacetone in chemostat culture. Archives of Microbiology 147, 268-275.

SweEtMan, A. J. \& Griffiths, D. E. (1971). Studies on energy linked reactions, an energy linked transhydrogenase reaction in Escherichia coli. Biochemical Journal 121, 125-130.

Teixeira de Mattos, M. J. \& Tempest, D. W. (1983). Metabolic and energetic aspects of the growth of Klebsiella aerogenes NCTC 418 on glucose in anaerobic chemostat culture. Archives of Microbiology 134, 80-85.

Teixeira de Mattos, M. J., Streexstra, H. \& Tempest, D. W. (1984). Metabolic uncoupling of substrate level phosphorylation in anaerobic glucose-limited chemostat cultures of Klebsiella aerogenes NCTC 418. Archives of Microbiology 139, 260-264. 